Arqueología y Sociedad,

№ 22, 2010

\title{
Más allá de Punta del Este. UNA MIRADA AL USO DEL BICROMADO EN EL ARTE RUPESTRE CUBANO
}

\author{
Divaldo Gutiérrez Calvache ${ }^{i}$ \\ José González Tenderoii \\ Racso Fernández Ortega $a^{i i i}$
}

\section{Resumen}

Se elabora un registro documental de las estaciones del arte rupestre cubano donde han sido utilizados dos colores o tonos en su ejecución. El registro enfrenta el problema hasta el nivel de sitio y sus características, proponiendo un modelo taxonómico simple para definir, organizar y clasificar las diferentes variantes del uso del bicromado en nuestro país. Finalmente, se realiza un breve comentario sobre las relaciones entre el bicromado, la superposición y los criterios cronológicos desarrollados sobre la base de esta problemática, lo que nos permite asegurar que se hace necesario incrementar y desarrollar nuestros modelos de análisis, pues el problema a que nos acercamos es complejo y solo puede ser abordado con métodos complejos de investigación.

\section{Palabras clave}

Arte rupestre, pictografías, colores, bicromado.

\begin{abstract}
It is produced a documentary record of the Cuban rock art stations where its have been used two colors or tones in its implementation. The record is facing the problem until the level of site and its features, by proposing a simple taxonomic model for define, organize and classify the different variants of the use of bichromate in our country. Finally, its been made a brief comment on relations between the bichromate, overlap and the time criteria developed at the base of this problem, allowing us to ensure that it is necessary to enhance and develop our analytical models, due to this problem that we are approaching is complex and can only be dealt with complex methods of investigation.
\end{abstract}

Keywords

Rock art, pictographs, colors, bichromate.

i Investigador Asociado. Máster en Administración. Grupo Cubano de Investigaciones del Arte Rupestre (GCIAR). Instituto Cubano de Antropología. Ministerio de Ciencia, Tecnología y Medio Ambiente.

Correo electrónico: 1lafer@infomed.sld.cu

ii Investigador Asociado. Grupo Cubano de Investigaciones del Arte Rupestre (GCIAR). Instituto Cubano de Antropología. Ministerio de Ciencia, Tecnología y Medio Ambiente.

Correo electrónico: marinaglez@infomed.sld.cu

iii Investigador Agregado. Máster en Antropología, Grupo Cubano de Investigaciones del Arte Rupestre (GCIAR). Instituto Cubano de Antropología. Ministerio de Ciencia, Tecnología y Medio Ambiente.

Correo electrónico: itibacahuababa@yahoo.com.ar 
... aun una clasificación al nivel de las propiedades sensibles es una etapa hacia un orden racional...

Lévi-Strauss

\section{INTRODUCCIÓN}

El uso del bicromado en los estudios rupestrológicos cubanos ha sido pocas veces abordado con un enfoque teórico y metodológico. Son escasos los trabajos que lo sitúan dentro de sus prioridades de investigación, aun cuando este es el más importante exponente de las relaciones de color en el arte rupestre de nuestro país, pues otras articulaciones de más de dos colores en un mismo conjunto son sumamente escasas y no superan valores del $1 \%$ de la gráfica rupestre nacional.

La primera referencia histórica al uso de dos colores en la ejecución de dibujos o pinturas rupestres cubanas se ubica en los manuscritos del Dr. Fernando Ortiz, sobre sus visitas a la Cueva No. 1 de Punta del Este, redactados probablemente entre los años 1922 y 1929. Estos documentos no fueron conocidos públicamente hasta que el investigador José Ramón Alonso Lorea los encontrara en el Fondo Fernando Ortiz de los Archivos de Literatura del Instituto de Literatura y Lingüística, en la carpeta 10, Arqueología (II), legajos 42 al 46; y se mantuvieron inéditos hasta que, en el año 2008, la paciente labor de dos importantes arqueólogos cubanos, el Dr. Pedro Pablo Godo y el MSc. Ulises González, permitió la publicación del volumen "La Cueva del Templo. Isla de Pinos. Los descubrimientos arqueológicos", donde, con las valoraciones críticas de estos investigadores, aparecen las notas de Ortiz. En esta obra se puede leer el siguiente testimonio: La rápida exploración que sobre el terreno pudo hacerse nos demostraron [sic] que las pinturas murales son más de cien, en su mayor parte formadas por circunferencias concéntricas, en color negro o rojo o en ambos colores combinados ${ }^{1}$, ora formando figuras aisladas o en complicadas uniones... (Ortiz 2008:56).

1 El subrayado es nuestro, y resalta la presencia del bicromado en la Cueva del Templo o Cueva No. 1 de Punta del Este, en la actual Isla de la Juventud.
Si bien es Ortiz el pionero en la apreciación in situ del bicromado en el arte rupestre de nuestro país, su análisis no va más allá de la simple observación y mención. Como señalan Pedro P. Godo y Ulises González, este sabio cubano no tuvo en cuenta en su estudio el principalísimo factor de los colores y sus combinaciones en el orden numérico (Godo y González, en Ortiz 2008: 22).

Con posterioridad a los manuscritos de Ortiz otros investigadores, como René Herrera Fritot (1939), Fernando Royo Guardia (1939), Antonio Núñez Jiménez (1947 y 1975), Esteban Maciques Sánchez (1983) y Martín Matos Socarrás (1985 y 1987), han hecho referencias y hasta inferencias sobre las posibles relaciones y significados, en cuanto a información social, que podrían transmitir o interpretarse del estudio del bicromado en la Cueva No. 1 de Punta del Este.

En este sentido, el aporte más preciso y organizado es, sin duda, el de José Ramón Alonso Lorea quien, a partir de su tesis de grado -titulada Arte Rupestre en Punta del Este: estética y símbolo, estructura y análisis (Alonso 1992)-, ha desarrollado una serie importante de investigaciones que presentan en conjunto, un novedoso modelo de análisis para esta variante gráfica, en las condiciones específicas de Punta del Este. Entre sus trabajos se pueden citar los dedicados, precisamente, a la obra hasta hace poco inédita de Ortiz (1993 y 2001); las propuestas sobre los conjuntos no concéntricos y concéntricos y sus colores (1991 a, b, c, d y 2003); y los artículos "Artes aborígenes en Cuba. Para un acercamiento teórico-metodológico a esta producción antigua" (1994) y "Panorama histórico-crítico sobre el estudio del arte rupestre de Punta del Este, Cuba" (2004).

Ahora bien, dentro de este horizonte, que abarca desde $1922^{2}$ hasta la fecha, todos los esfuerzos encaminados a establecer algún modelo de análisis sobre variables, invariables, distribución, organización, categorización, etc., de los diseños bicromados en el arte rupestre cubano fueron particularmente dirigidos hacia la Cueva

2 Fecha en que Fernando Ortiz redescubre la Cueva del Templo o Cueva No. 1 de Punta del Este. 

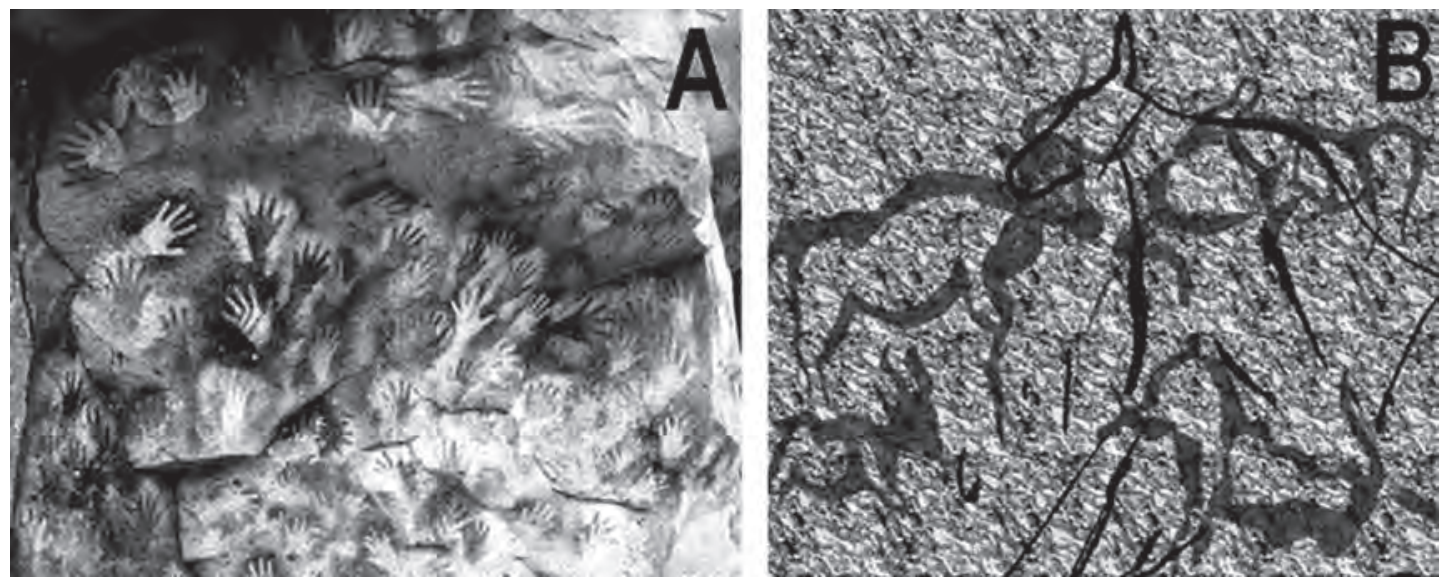

Figura 1. Ejemplos del uso del bicromado en la composición de diseños en el arte rupestre mundial.

(A) Cueva de la Manos, Santa Cruz, Argentina y (B) Sitio La Pileta, Málaga, España.

No. 1 de Punta del Este, limitándose las referencias a esta problemática en otras localidades a escasas citas, como: "existen dibujos realizados en negro y rojo" o "este diseño está elaborado en rojo y negro" 3 . Esta realidad fue creando las bases para la conformación de Punta del Este (en especial de la Cueva No. 1) como un patrón o símbolo absoluto, de forma tal que son hoy escasos los arqueólogos, historiadores o antropólogos cubanos que, al ser consultados sobre la presencia de diseños bicromados en nuestra gráfica rupestre, lograrían que su respuesta exceda los límites geográficos de la actual Isla de la Juventud; y muchos se conformarían, seguramente, con recordarnos la existencia de la Cueva No. 1 de Punta del Este.

Es por ello que emprendimos la realización de esta monografía, en la cual no presentamos al lector un profundo estudio de las implicaciones que, en términos de información social o de arqueología del detalle, deben estar presentes en la decisión de utilizar una paleta bicromada en la ejecución de un motivo o diseño rupestre; sino que, en esencia, pretendemos sacar del abandono un grupo importante de localidades que no por escasas han de ser ignoradas, pues son ellas en conjunto el abanico de opciones funcionales, psicológicas, mágicas, mitológicas, etc.,

3 Ver, por ejemplo, las descripciones del arte rupestre de las Cuevas de García Robiou y de Ambrosio, en "Cuba: Dibujos Rupestres" (Núñez, 1975). que determinaron la presencia de esta peculiar forma de ejecutar una pintura rupestre en nuestras condiciones geo-históricas o prehistóricas. Organizar la información existente, categorizarla y clasificarla, es el comienzo de un enfoque científico; el caos, por su parte -de mantenerse-, estimula nuestra ignorancia: razón de más, entonces, para acometer este trabajo.

\section{Conceptos, modelos y categorías para Cuba}

Es trascendental definir aquí qué entendemos por bicromado en arte rupestre y cómo este se manifiesta en las condiciones del archipiélago cubano. Desde el punto de vista conceptual, el bicromado, como su nombre lo indica, es el uso de dos colores o tonos en la ejecución de imágenes de cualquier tipo, sobre cualquier soporte.

En arte rupestre, el bicromado es, entonces, el resultado de la elaboración de pinturas, dibujos o bocetos, realizados sobre superficies rocosas sedentes o mobiliares, mediante el uso de dos colores o tonos. Pinturas rupestres bicromadas son conocidas en casi todo el mundo, exceptuando la Antártida, y en casi toda las etapas del desarrollo del hombre (Fig. 1). Las variantes de sus modos de ejecución son numerosas, pasando desde el "simple" delineado en dos colores (Fig. 1B) hasta las complejas relaciones de ejecución bicromada presentes en la Cueva de las Manos, Santa Cruz, Argentina (Fig. 1A). 
Sin embargo, dentro del concepto citado se puede aislar, al menos para Cuba, más de un modelo de análisis. Nos referimos a la implicación espacial en el uso de los colores o tonos, pues se hace necesario distinguir el bicromado que tiene un carácter local, sitial o estacional, del que se presenta formando parte integral de diseños, conjuntos o murales.

El primero de estos modelos se refiere a lo que proponemos definir como "Estaciones de contexto bicromado" (ECB). Son aquellos sitios o localidades donde aparecen diseños pictográficos elaborados en uno u otro color; pero donde la dualidad tonal no se articula en un diseño común, o sea, cada diseño en sí mismo es monocromático. Una estación de referencia para esta propuesta es, sin lugar a dudas, la Cueva de la Pluma en Cumbre Alta, Matanzas.

En Cuba estas estaciones se caracterizan por el uso del negro y el rojo, mayoritariamente;

\begin{tabular}{|c|c|c|c|c|}
\hline NOMBRE DE LA ESTACION & PROVINCIA & MUNICIPIO & $\mathrm{ECB}$ & EDB \\
\hline Cueva de Camila & \multirow{9}{*}{ Pinar del Río } & Minas de Matahambre & & $\mathrm{X}$ \\
\hline Solapa de la Perdiguera & & Minas de Matahambre & & $\mathrm{X}$ \\
\hline Solapa de los Pintores & & Minas de Matahambre & & $\mathrm{X}$ \\
\hline Solapa de los Círculos & & Minas de Matahambre & $\mathrm{X}$ & \\
\hline Solapa del Abrón & & La Palma & & $\mathrm{X}$ \\
\hline Cueva del Garrafón & & Viñales & $\mathrm{X}$ & \\
\hline Cueva de la Mancha & & Viñales & $\mathrm{X}$ & \\
\hline Cueva del Cura & & Viñales & $\mathrm{X}$ & \\
\hline Cueva la Espiral & & Bahía Honda & $\mathrm{X}$ & \\
\hline Cueva No. 1 de Punta del Este & \multicolumn{2}{|c|}{ Municipio Especial Isla de la Juventud } & & $\mathrm{X}$ \\
\hline Cueva No. 2 de Punta del Este & \multicolumn{2}{|c|}{ Municipio Especial Isla de la Juventud } & & $\mathrm{X}$ \\
\hline Cueva No. 3 de Punta del Este & \multicolumn{2}{|c|}{ Municipio Especial Isla de la Juventud } & & $\mathrm{X}$ \\
\hline Cueva de Finlay & \multicolumn{2}{|c|}{ Municipio Especial Isla de la Juventud } & & $\mathrm{X}$ \\
\hline Cueva de la Virgen & Ciudad de La Habana & Habana del Este & $\mathrm{X}$ & \\
\hline Cueva de García Robiou & La Habana & Güines & & $\mathrm{X}$ \\
\hline Cueva de Ambrosio & Matanzas & Varadero & & $\mathrm{X}$ \\
\hline Cueva de la Pluma & Matanzas & Matanzas & $\mathrm{X}$ & \\
\hline Cueva del Chino & \multirow{5}{*}{ Sancti Spíritus } & Yaguajay & $\mathrm{X}$ & \\
\hline Solapa de Pulido & & Yaguajay & $\mathrm{X}$ & \\
\hline Cueva de Las Conchas & & Yaguajay & $\mathrm{X}$ & \\
\hline Cueva de Los Chivos & & Yaguajay & & $\mathrm{X}$ \\
\hline Cueva Grande de Punta Judas & & Yaguajay & $\mathrm{X}$ & \\
\hline Cueva de Matías & \multirow{2}{*}{ Camagüey } & Sierra de Cubitas & $\mathrm{X}$ & \\
\hline Cueva de Las Mercedes & & Sierra de Cubitas & $\mathrm{X}$ & \\
\hline \multicolumn{3}{|c|}{ TOTALES } & 13 & 11 \\
\hline
\end{tabular}

Tabla I. Localidades del arte rupestre cubano pertenecientes a los modelos propuestos como

"Estaciones de contexto bicromado" (ECB) y "Estaciones de diseños bicromados" (EDB). 


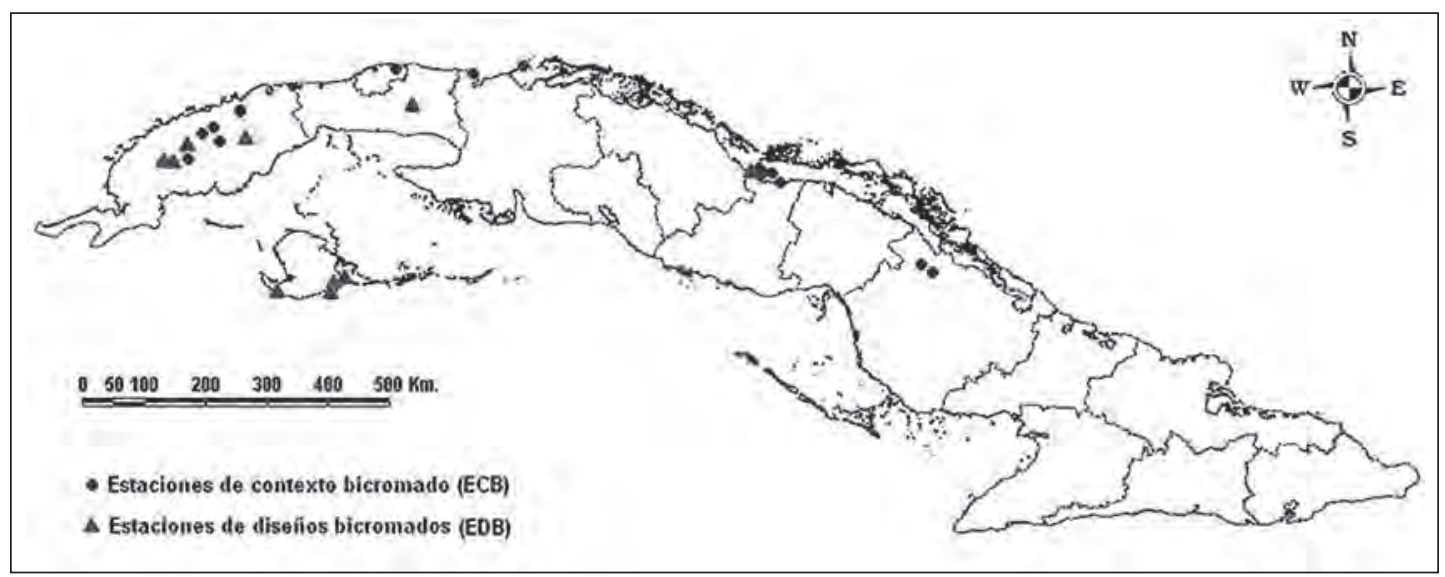

Figura 2. Distribución geográfica del arte rupestre bicromado en Cuba.

sin embargo, existen otras combinaciones de los tonos anteriores con el blanco y el sepia, indistintamente. Su distribución geográfica (Fig. 2) se puede establecer, según el estado actual de las investigaciones, en el área que ocupan las macroregiones geo-arqueológicas central y occidental del arte rupestre cubano, o sea, desde la provincia de Camagüey hasta Pinar del Río (Gutiérrez, Fernández y González, et al. 2009). Este modelo lo hemos aislado en 13 estaciones (Tabla I), que constituyen el $5.3 \%$ del total de estaciones del país (Gutiérrez, Fernández y González, et al. 2009).

El segundo de los modelos, que proponemos definir como "Estaciones de diseños bicromados" (EDB), se refiere a aquellos sitios o localidades donde aparecen diseños, dibujos o conjuntos pictográficos elaborados en dos tonos, dentro de la articulación propia del diseño. Hasta hoy en nuestro país solo se ha documentado la utilización simultánea del rojo y el negro. Son estaciones típicas de este modelo la Cueva No. 1 de Punta del Este, en la Isla de la Juventud y la Cueva de García Robiou, en Güines, La Habana. Es importante señalar que en este modelo es posible encontrar también diseños monocromáticos -en negro, blanco, sepia, gris o rojo- dentro de la estación, o sea, pueden aparecer en estas estaciones características de las ECB. Su distribución geográfica (Fig.
2) también se circunscribe a las macroregiones geo-arqueológicas central y occidental, aunque en este caso su presencia hacia el este solo llega al territorio de Sancti Spíritus. De este modelo hemos aislado 11 estaciones (Tabla I), para un $4.5 \%$ del total de estaciones del arte rupestre cubano (Gutiérrez, Fernández y González, et al. 2009).

Hasta aquí se ha establecido la existencia en nuestro país de dos modelos de distribución conceptual y espacial del bicromado en los sitios o estaciones rupestres. Sin embargo, en el proceso de análisis se devela que, al menos en el segundo de los modelos (EDB), se pueden proponer algunas categorías de tipo conceptual hacia el interior de los propios diseños bicromados. No debemos abordar con un enfoque común diseños donde se alternan rítmicamente círculos concéntricos rojos y negros, o donde a una figura zoomorfa realizada en negro se le superpone una figura antropomorfa de color rojo, o donde en una misma figura se han utilizado dos colores.

Siguiendo este criterio, nuestra propuesta taxonómica para organizar el conocimiento que hoy tenemos del uso del bicromado en el arte rupestre cubano se puede construir según los modelos antes discutidos y las categorías que explicamos a continuación: 


\begin{tabular}{|l|l|l|}
\hline CONCEPTO & MODELOS & CATEGORIAS \\
\hline \multirow{3}{*}{$\begin{array}{l}\text { Bicromado en el arte } \\
\text { rupestre cubano }\end{array}$} & $\begin{array}{l}\text { Estaciones de contexto } \\
\text { bicromado (ECB) }\end{array}$ & \\
\cline { 2 - 3 } & $\begin{array}{l}\text { Estaciones de diseños } \\
\text { bicromado (EDB) }\end{array}$ & Diseños bicromados alternos (DBA) \\
\cline { 2 - 3 } & Diseños bicromados en composición (DBC) \\
\cline { 2 - 3 } & Diseños bicromados en superposición (DBS) \\
\hline
\end{tabular}

Tabla II. Propuesta de organización taxonómica para las diferentes variantes de uso del bicromado en el arte rupestre cubano.

\section{Diseños bicromados alternos (DBA)}

Constituyen aquellos diseños pictográficos ${ }^{4}$ que se relacionan de forma armónica entre sí y que fueron elaborados mediante el uso de dos colores de forma alterna ${ }^{5}$, dándole al conjunto una importante simetría del color. Los valores cuantitativos del ritmo alternativo pueden ser muy variados; pero tienen un importante grado de sistematicidad rítmica.

El ejemplo más importante de esta categoría lo constituyen los círculos concéntricos de la Cueva No. 1 de Punta del Este, donde es significativa la abundancia y sistematicidad del ritmo, aun cuando se pueden apreciar en esta localidad diferentes variantes como, por ejemplo, las relaciones negro-rojo, negro-negro-rojo-negro, etc. (Fig. 3A). Estas y otras variantes desde el punto de vista cuantitativo han sido estudiadas en detalle por Lorea (2003).

\section{Diseños bicromados en composición (DBC)}

Son aquellos diseños pictográficos constituidos por figuras combinadas e independientes ejecutadas en dos colores, unas de un color y otras de otro. ${ }^{6}$ En esta categoría la composición del diseño puede llegar hasta la tangencia de los motivos que lo conforman, pero nunca presentan sobreposición tonal, o sea, nunca un tono cubre a otro, ni total ni parcialmente.

4 El concepto de "diseño pictográfico" no distingue otros valores cualitativos como motivo, pintura, dibujo, etc., propuestos en la rupestrología cubana; pero que, en este trabajo, carecen de trascendencia y valor informativo.

567 Hasta hoy, para estos tipos de diseños, solo ha sido reportado el uso del negro y el rojo.
Uno de los ejemplos más importantes de esta categoría se localiza en la Cueva de los Chivos, municipio de Yaguajay, Sancti Spíritus, donde aparece un hermoso conjunto pictográfico formado por tres motivos, dos elaborados en tonos de rojo y un tercero en negro (Fig. 3B).

\section{Diseños bicromados en superposición (DBS)}

Son aquellos diseños pictográficos bicromados en los cuales aparecen motivos elaborados tanto en un color como en otro ${ }^{7}$, pero superpuestos indistintamente; dándole al conjunto una singular importancia: estas superposiciones pueden ser vehículos de importantes informaciones relacionadas con conceptos estilísticos, valores cronológicos y concepciones ideológicas.

El ejemplo típico de esta categoría lo constituyen algunos diseños de la Solapa de los Pintores, municipio Minas de Matahambre, Pinar del Río, donde, dentro de un complejo conjunto pictográfico bicromado, aparecen importantes superposiciones tonales (Fig. 3C).

Desde el punto de vista de la frecuencia de la relación entre las diferentes categorías de diseños bicromados y las estaciones del arte rupestre en que se encuentran, es el diseño en composición (DBC) el que más aparece, con una frecuencia del $81.8 \%$, es decir, está presente en nueve de las once estaciones estudiadas; en contraposición con los diseños alternos (DBA) y los de superposición (DBS), que se reportan solo en cuatro y cinco estaciones, respectivamente, lo que representa el $36.4 \%$ y el $45.5 \%$ de frecuencia (Tabla III). Por otro lado, la estación Cueva No. 1 de Punta del Este es la única en la que 

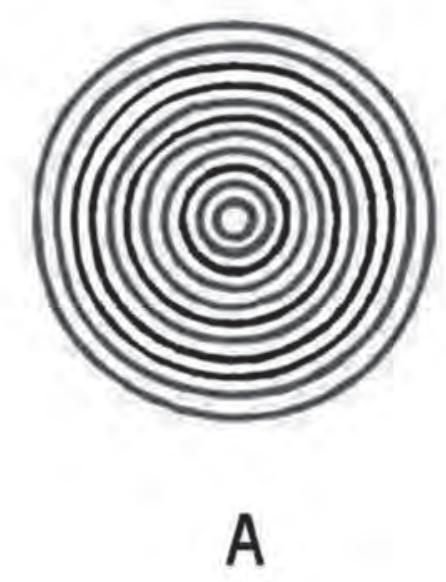

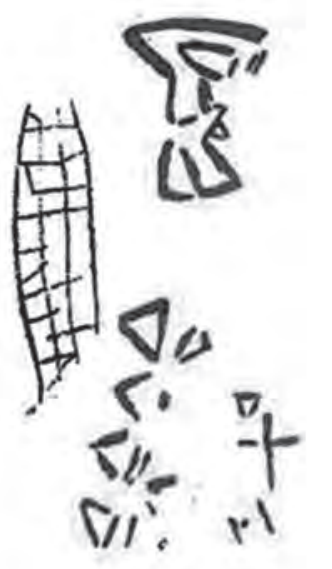

B
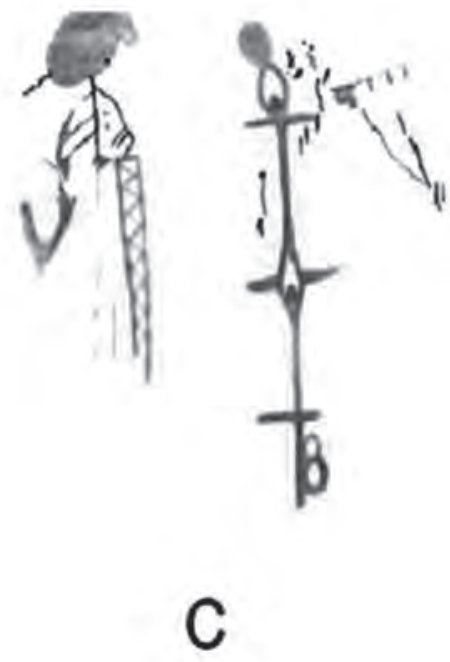

Figura 3. Variantes de las diferentes categorías de diseños bicromados en el arte rupestre cubano. (A) Pictografía de la Cueva No. 1 de Punta del Este: diseño bicromado alterno; (B) Pictografía de la Solapa de la Cueva de los Chivos, Yaguajay, Sancti Spíritus: diseño bicromado en composición y (C) Pictografía de la Solapa de los Pintores, Minas de Matahambre, Pinar del Río: diseño bicromado en superposición.

(Fuente: Lorea, 2003 y dibujos originales de Alejandro Romero Emperador e Hilario Carmenate).

se han logrado identificar las tres categorías de diseños propuestas.

Finalmente, para concluir la organización de las diferentes categorías de diseños bicromados en el arte rupestre cubano, hay que dejar claro que estas pueden presentarse $-\mathrm{y}$ de hecho lo hacen- de forma combinada, es decir, que aparecen conjuntos pictográficos en los cuales se reporta más de una categoría. Ejemplos de esto son la Solapa del Abrón, La Palma, Pinar del Río, donde en un mismo diseño se observan elementos bicromados en composición y

\begin{tabular}{|c|c|c|c|c|c|}
\hline NOMBRE DE LA ESTACION & PROVINCIA & MUNICIPIO & DBA & $\mathrm{DBC}$ & DBS \\
\hline Cueva de Camila & \multirow{4}{*}{ Pinar del Río } & Minas de Matahambre & & $\mathrm{X}$ & $\mathrm{X}$ \\
\hline Solapa de la Perdiguera & & Minas de Matahambre & & $\mathrm{X}$ & \\
\hline Solapa de los Pintores & & Minas de Matahambre & & $\mathrm{X}$ & $\mathrm{X}$ \\
\hline Solapa del Abrón & & La Palma & & $\mathrm{X}$ & $\mathrm{X}$ \\
\hline Cueva No. 1 de Punta del Este & \multicolumn{2}{|c|}{ Municipio Especial Isla de la Juventud } & $\mathrm{X}$ & $\mathrm{X}$ & $\mathrm{X}$ \\
\hline Cueva No. 2 de Punta del Este & \multicolumn{2}{|c|}{ Municipio Especial Isla de la Juventud } & $\mathrm{X}$ & $\mathrm{X}$ & \\
\hline Cueva No. 3 de Punta del Este & \multicolumn{2}{|c|}{ Municipio Especial Isla de la Juventud } & $\mathrm{X}$ & & \\
\hline Cueva de Finlay & \multicolumn{2}{|c|}{ Municipio Especial Isla de la Juventud } & $\mathrm{X}$ & & \\
\hline Cueva de García Robiou & La Habana & Güines & & $\mathrm{X}$ & \\
\hline Cueva de Ambrosio & Matanzas & Varadero & & $\mathrm{X}$ & $\mathrm{X}$ \\
\hline Cueva de Los Chivos & Sancti Spiritus & Yaguajay & & $\mathrm{X}$ & \\
\hline \multicolumn{3}{|c|}{ TOTALES } & 4 & 9 & 5 \\
\hline
\end{tabular}

Tabla III. Frecuencia de la relación Categoría de diseños - Estaciones de diseños bicromados. 


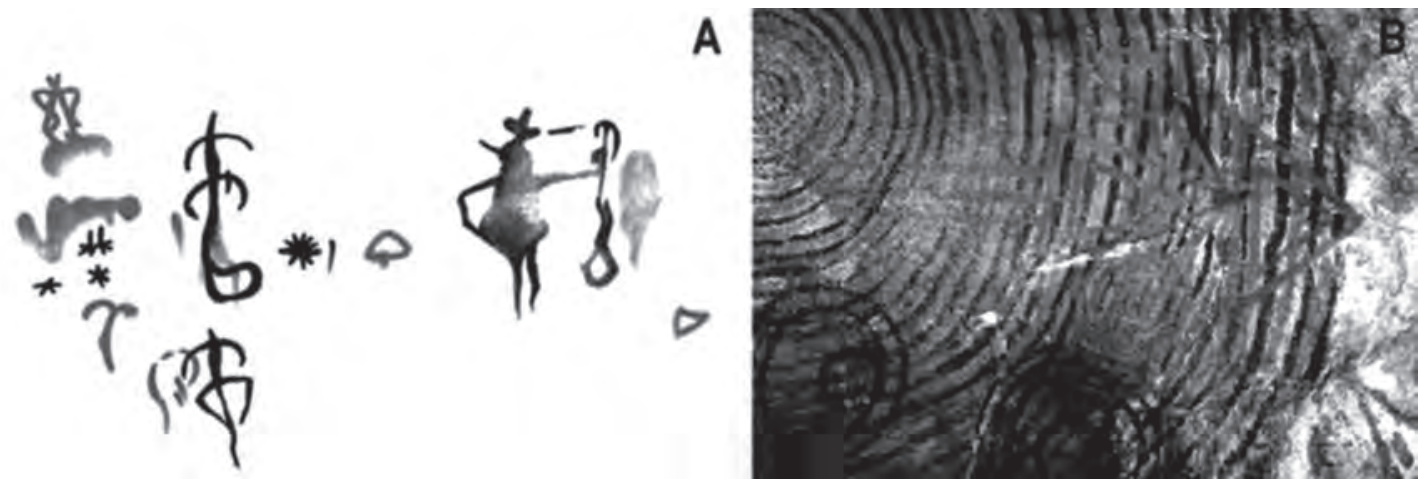

Figura 4. Ejemplos de estaciones pictográficas donde se evidencia la combinación de más de una categoría de diseños bicromados. (A) Cueva del Abrón, La Palma, Pinar del Río y (B) Cueva No. 1 de Punta del Este, Isla de la Juventud (Fuente: Archivos del GCIAR y dibujos originales de Hilario Carmenate).

en superposición (Fig. 4A); o la Cueva No. 1 de Punta del Este, donde se aprecian elementos alternos y en superposición en el mismo diseño bicromado (Fig. 4C).

\section{LOS DISEÑOS BICROMADOS EN EL PANORAMA ARQUEOLOGICO CUBANO}

Como ya expresamos con anterioridad, no es nuestro propósito realizar un estudio interpretativo del uso del bicromado en el arte rupestre cubano. No obstante, sí creemos oportuno comentar, a manera de reflexión, algunos criterios que han rodeado esta problemática y que, por más que queramos, no podemos ignorar ni dejar al margen en este trabajo.

Entre tales aspectos resalta uno de los más controvertidos y polémicos temas de nuestra especialidad: el cronológico; en este caso manejando conceptos que podríamos definir como "crono-tonales", o sea, el uso de cambios en los tonos del arte rupestre como elemento crono diagnóstico.

La presencia de una paleta bicromada en la ejecución del arte rupestre implica siempre una secuencia cronológica en el uso de uno u otro tono, aun cuando dicha secuencia sea inmediata. Sin embargo, esta realidad es en extremo compleja y difícil de esclarecer y organizar, lo cual en muchos casos limita considerablemente nuestra reconstrucción arqueológica.
Pongamos un ejemplo: la realización de lo que hemos definido como diseños bicromados alternos (DBA) sugiere, en la mayoría de los casos, una secuencia de ejecución continua e inmediata; ahora bien, si utilizamos para este análisis los círculos concéntricos bicromados de la Cueva No. 1 de Punta del Este, cabría preguntarnos ino fue posible la ejecución primaria de los círculos rojos (o negros) y la posterior ejecución de los otros?

Este y otros cuestionamientos continúan sin respuesta, aun cuando algunos investigadores han sugerido que: ". . los trazos negros se imponen por su cantidad a los trazos rojos, considerando que el círculo rojo induce a inferir ${ }^{8}$ que este fuese la nota de diferenciación dentro de la serie, siendo el trazo negro la base de su conformación..." (Alonso, 2003).

Por otra parte, autores como el Dr. Antonio Núñez Jiménez han indicado, para el caso que tratamos, que "...el color rojo, cuando aparece combinado con el negro, siempre está pintado sobre este..." (Núñez 1947:82). Aquí habría que analizar que entiende este autor por "combinado", pues la simple observación in situ del arte rupestre de esta localidad (Fig. 4B) nos demuestra que existen series de círculos rojos sobrepuestas a trazos negros y series negras superpuestas a trazos rojos.

\footnotetext{
8 El subrayado es nuestro.
} 
Lo cierto es que en Punta del Este, y en la mayoría de las estaciones con presencia de diseños bicromados alternos, las preguntas sin respuestas, o las respuestas cuestionables, son mucho más abundantes que lo que realmente quisiéramos los rupestrólogos. De cualquier manera, lo más razonable es que el autor, antes de iniciar el dibujo, tuviera concebido el diseño final, y realizara los primeros trazos a continuación de los segundos, sin que mediase un prolongado período de tiempo entre la ejecución de ambos; pero esta es otra de las especulaciones que constituyen "preguntas sin respuestas" o "respuestas cuestionables". Recordemos que para estos grupos humanos el dibujo rupestre no era un simple acto de creación estética, sino que formaba parte de una acción ideológica de amplio sentido ritual y social.

Otro caso peculiar en este panorama son aquellas estaciones donde aparecen diseños bicromados en composición (DBC). Esta categoría permite muy pocas posibilidades de ordenamiento crono-tonal debido, sobre todo, a que casi siempre que aparece en Cuba, en ella están ausentes otros elementos cronológicos, como diferencias en el tipo e intensidad de las coberturas o de las patinas, distinciones estilísticas notables, etc., lo que, junto a la ausencia general de superposiciones o yuxtaposiciones, entorpece su clasificación secuencial. Un ejemplo singular es la Cueva de García Robiou, en Güines, La Habana, donde existe un hermoso diseño bicromado en composición (Fig. 5E y 5F), descrito por Núñez Jiménez de la siguiente forma:

“...figura femenina formada por un círculo de color rojo en cuyo interior aparece un redondel de color negro a tinta llena que cubre casi toda la parte interna del círculo, en cuya parte derecha superior hay un punto rojo que parece un ojo; debajo y como sosteniendo la figura anteriormente descrita aparece el "cuerpo" como formado por una especie de trapecio o cuadrilátero en cuya parte interna presenta finísimos trazos negros que semejan 'costillas' formadas por figuras angulares y superpuestas cuyos vértices apuntan hacia arriba; una línea central corta estas 'costillas' formando como la 'columna' de un cuerpo. El hecho de que en esta figura puedan verse las 'costillas' y la "columna" nos permite conceptuarla como 'radiográfica', cosa común en Australia y otros países. Sobre 'la cabeza' aparecen como dos "adornos" formados por líneas y un semicírculo. En total, la figura tiene $34 \mathrm{~cm}$ de alto por $17 \mathrm{~cm}$ de ancho. Las 'costillas' tienen $1 \mathrm{~mm}$ de ancho mientras que el trapecio mide $10 \mathrm{~mm}$ de ancho, y la base 4 cm..." (Núñez 1967: 58).

El análisis crono-tonal, en el diseño antes comentado y en esa localidad en general, es un reto al investigador, pues no hay el más mínimo elemento de certeza para ordenar la forma en que se utilizaron los diferentes tonos de la paleta de ejecución.

Menos comunes en nuestro panorama rupestrológico son aquellas estaciones donde se combinan en un conjunto pictográfico diferentes categorías de diseños que, si bien no nos dan opciones precisas, sí permiten, al menos, realizar inferencias para una organización teórica que nos acerque a un modelo susceptible de ser comprobado científicamente. Como ejemplos pueden citarse la Cueva de Camila, Minas de Matahambre (Fig. 5C y 5D) y la Solapa del Abrón, en la Palma (Fig. 4A), ambas en Pinar del Río. En estas localidades se observa, en un mismo conjunto, la presencia de diseños en superposición que permiten asumir como modelo a comprobar la primaria utilización del rojo, pues en todos los casos el negro está sobrepuesto a los tonos en rojo.

Dentro de esta problemática se incluye también el análisis de aquellos diseños bicromados en superposición que han sido interpretados como modelos de superposición cultural, o sea, diseños donde algunos investigadores creen ver que un color fue utilizado por un grupo cultural y el segundo por otro grupo. Si bien esto es perfectamente posible en una reconstrucción arqueológica, la realidad que encontramos en nuestras estaciones limita tal reconstrucción desde el punto de vista de su comprobación en el campo.

Veamos, por ejemplo, la Solapa de los Pintores, Minas de Matahambre, Pinar del Río (Fig. $5 \mathrm{~A}$ y $5 \mathrm{~B})$. El debate académico sobre la filiación 

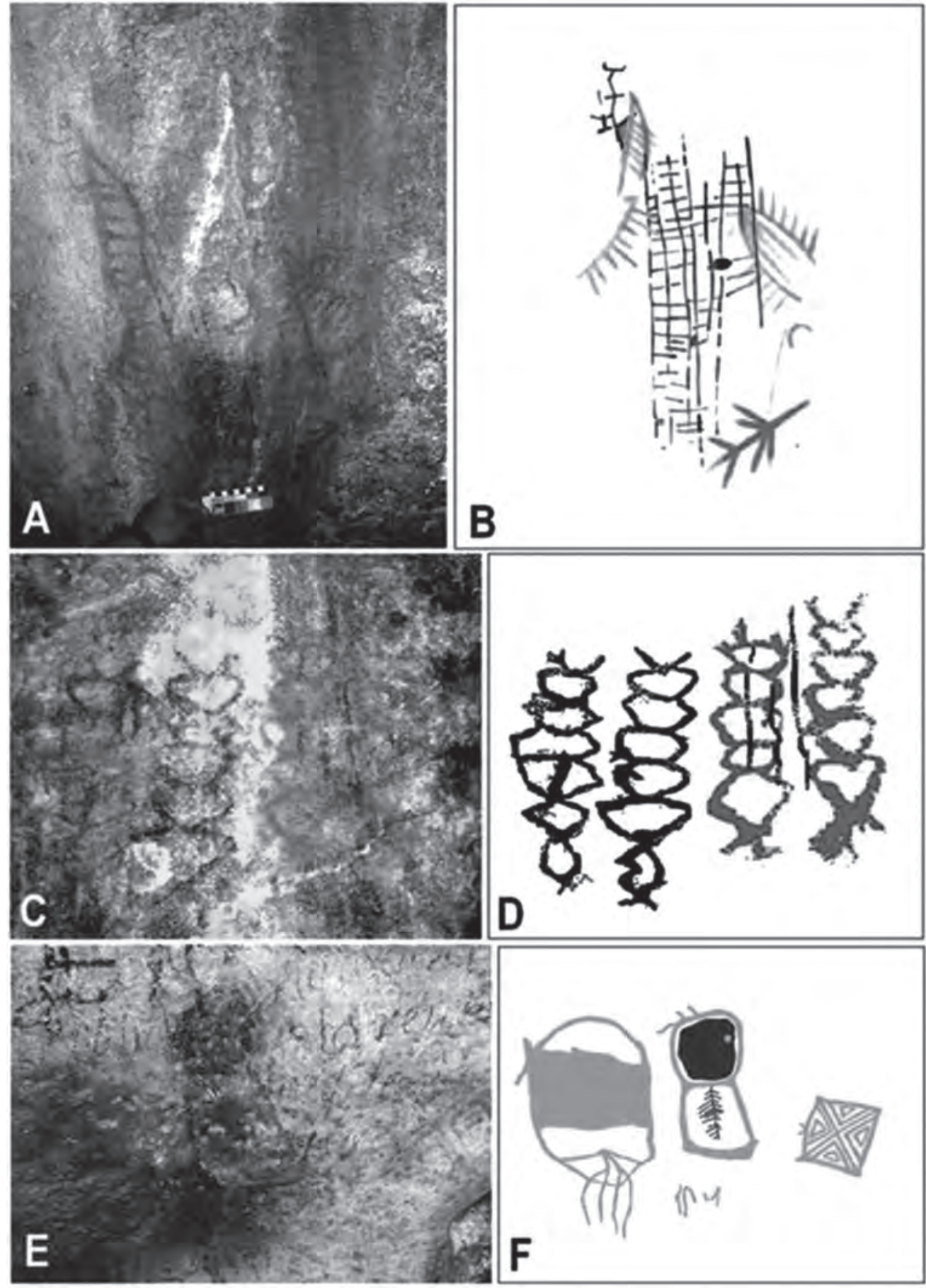

Figura 5. Diferentes ejemplos de diseños bicromados en el arte rupestre cubano. (A y B) Fotografía y dibujo de un diseño de la Solapa de los Pintores, (C y D) Fotografía procesada por DStrech y dibujo de una pictografía de la Cueva de Camila, (E y F) Fotografía y dibujo de una pictografía de la Cueva de García Robiou (Fuente: Archivos del GCIAR, Núñez Jiménez, 1985 y dibujos originales de Hilario Carmenate). 
de sus pictografías ha implicado, indistintamente, a grupos aborígenes y a esclavos africanos huidos de las plantaciones entre los siglos XVI y XIX, como autores absolutos o en etapas sucesivas de ocupación. Al respecto, la autoría de origen africano exclusiva ha sido puesta en dudas después de que una reciente expedición del Grupo Cubano de Investigaciones del Arte Rupestre encontrara numerosa evidencia artefactual aborigen en la localidad (Fig. 6), sin que hasta hoy hayan sido recuperadas evidencias de ocupación en la etapa colonial.

Por otro lado, se ha llegado a distribuir el arte rupestre de forma monocromática para cada etapa o grupo cultural, sin detenerse en el análisis detallado de todos y cada uno de los diseños. Sin embargo, al menos en esta estación, los conjuntos bicromados en superposición presentan dos variantes bitonales: en algunos lugares de un mismo diseño, el rojo se sobrepone al negro y en otros, a la inversa, lo que limita las inferencias basadas en la relación etno-colorcronología.

Vale subrayar que el bicromado en arte rupestre ha sido históricamente utilizado por los grupos precolombinos del Caribe, y no necesariamente debe estar asociado a momentos cronológicamente distantes y con diferencia cultural, tendencia bastante arraigada entre los rupestrólogos cubanos.

Ahí está Punta del Este, y su relación con nuestros grupos pescadores-cazadores-recolectores. Si algún cuestionamiento existiera en este sentido, debemos recordar que el uso del bicromado en nuestra región trascendió el arte rupestre, para aparecer también en la alfarería: es verdaderamente admirable el tratamiento decorativo en rojo y blanco de la cerámica asociada a los grupos saladoides (Igneri), la cual no llego a desarrollarse en Cuba, pero se extendió con fuerza por todo el Caribe insular hasta la vecina isla de Puerto Rico (Fig.7).

Finalmente, queremos referirnos a la estación conocida como Cueva de Ambrosio, Varadero, Matanzas. Para esta localidad también se ha considerado la posibilidad de una superposición cultural en su arte rupestre basándose, generalmente, en la interpretación contemporánea de la morfología de los pictogramas, acompañada, en ocasiones, de pinceladas de algún análisis semiótico. Así, algunos han pretendido ver dos momentos aborígenes, y otros, uno aborigen y otro africano (Núñez 1975:136; Pereira 2004).

La defensa de esta superposición cultural en algunos debates académicos ha requerido de numerosos argumentos. Entre ellos está -y es el que aquí nos interesa- la superposición presente en uno de sus más conocidos diseños (fig. $8 \mathrm{~A}$ ), donde a los trazos negros se les asigna una autoría africana, y a los rojos una aborigen.

Sin embargo, la desarticulación de dicho diseño nos pone en una situación bien difícil. Como se puede observar en las figuras $8 \mathrm{~B}$ y $8 \mathrm{C}$, al separar los trazos negros no logramos recuperar lo que había de rojo bajo estos, quedando para el análisis unas escasas líneas de difícil interpretación, lo cual, a nuestro juicio, invalida este proceder, y no permite un ordenamiento del diseño rojo dentro del contexto propio de la estación y mucho menos del regional o cultural.

Todos estos problemas permanecerán entre las grandes incógnitas de nuestra arqueología por buen tiempo. $\mathrm{Al}$ asumir que los diseños bicromados en superposición en el arte rupestre pueden transmitir información crono-cultural, se hace necesario explorar otros caminos que nos brinda la arqueología. Sería prudente tratar de esclarecer qué razones ideológicas podrían haber motivado que un africano decidiera reutilizar el mismo espacio pictórico que utilizó un aborigen, aun cuando existían otras opciones espaciales. Asimismo, se hace necesario incrementar los esfuerzos en el análisis químico de los materiales de ejecución, a fin de tratar de identificar complejos de similitud o diferencia en el orden cultural y material.

Un importante campo no abordado con profundidad lo constituye la relación entre diseños bicromados y la utilización del rojo en 


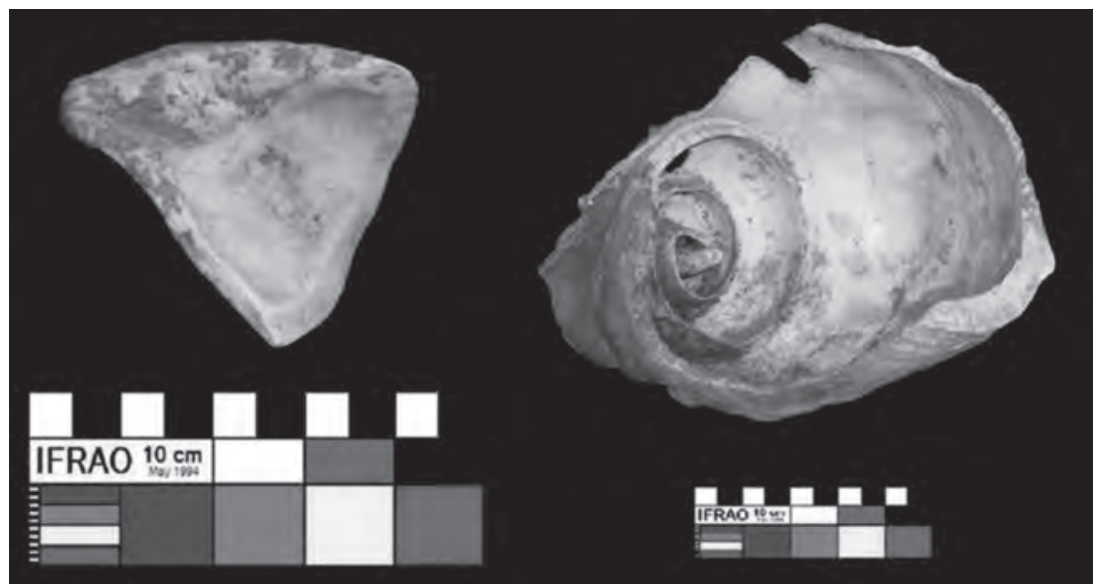

Figura 6. Muestra de las evidencias materiales encontradas en la Solapa de los Pintores por la expedición del Grupo Cubano de Investigaciones del Arte Rupestre (Fuente: González, et al. 2007).

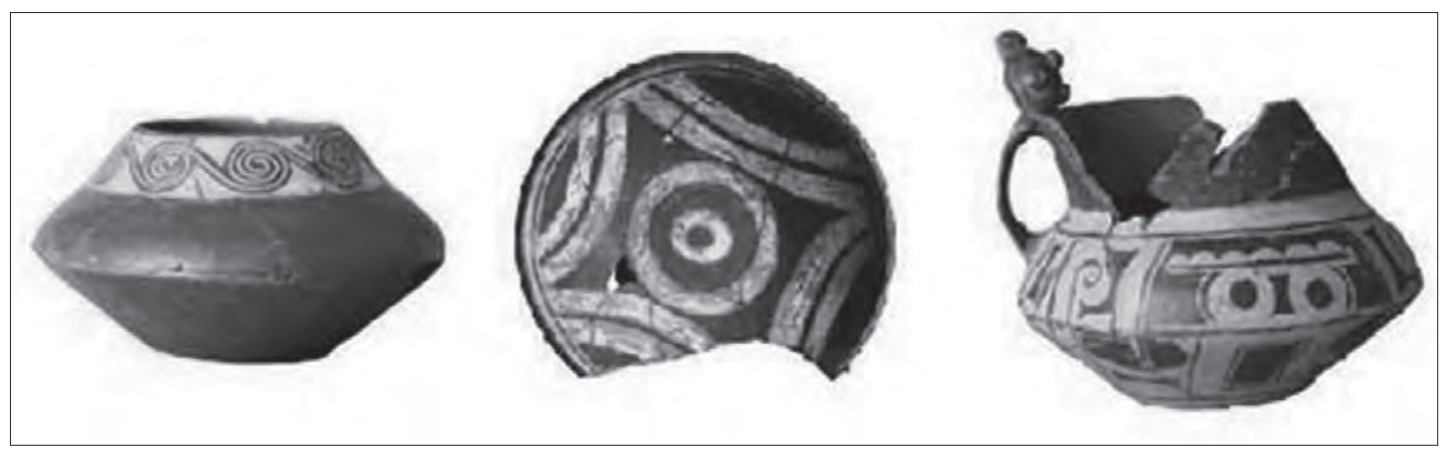

Figura 7. Vasijas cerámicas de grupos saladoides localizadas en sitios de Puerto Rico, decoradas en tonos de blanco y rojo. (Fuente: Universia, publicación OnLine de la Universidad de Puerto Rico).
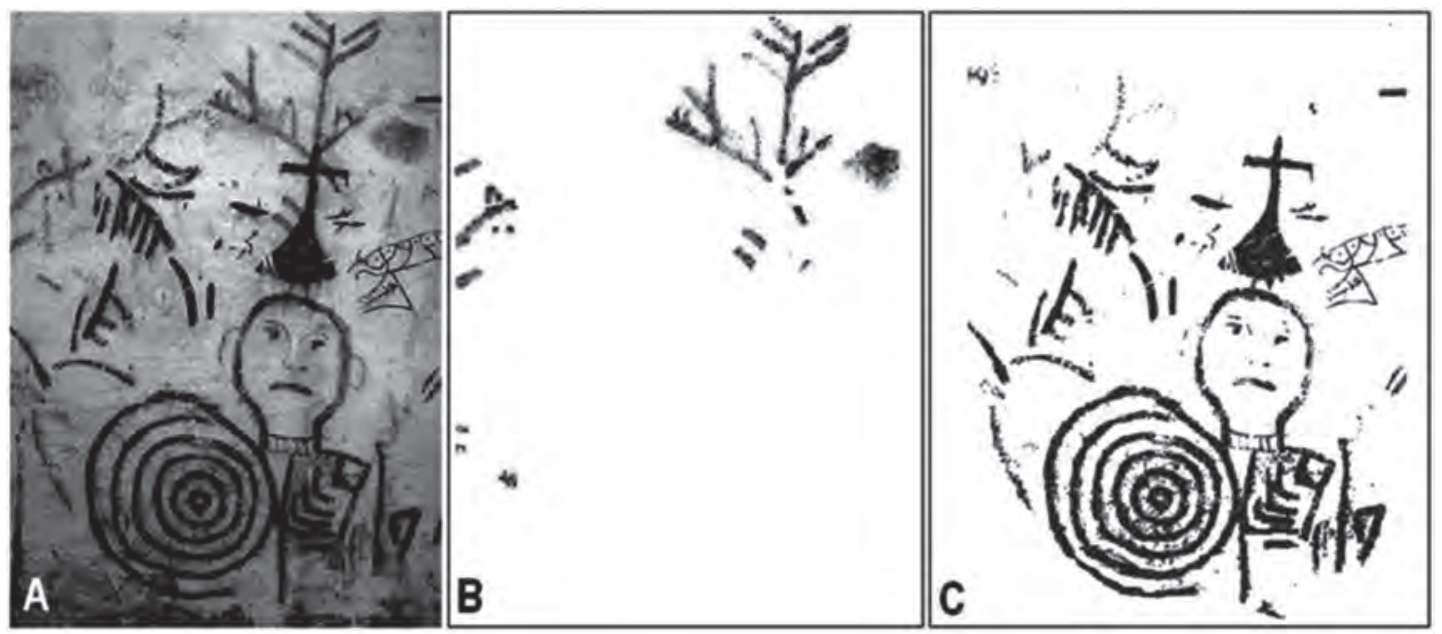

Figura 8. Diseño bicromado en composición de la Cueva de Ambrosio, Varadero, Matanzas y su descomposición por medio del software Photo Shop 8.5. (A) Fotografía del diseño, (B) Descomposición de los tonos en rojo y (C) Descomposición de los tonos negros. 
procedimientos funerarios en el entorno de las estaciones. Esta temática solo ha sido abordada en una ocasión en los estudios rupestrológicos cubanos (Fernández 1994), pero la línea de investigación no estaba orientada a la relación con las estaciones de contextos o diseños bicromados.

Estos y otros cuestionamientos podrían abrirnos el camino y permitirnos desentrañar esta curiosa e importante relación en los diferentes complejos tonales del arte rupestre cubano.

\section{CONClusiones}

Realizada la organización y caracterización de la presencia del bicromado en el arte rupestre cubano, queda claro que, en la actualidad, el análisis no nos permite obtener respuestas definitivas.

Este ordenamiento sitúa en el campo de la duda los criterios crono-tonales sugeridos en diferentes ambientes académicos: la evaluación detallada no refleja, con claridad, confiables elementos cronológicos y mucho menos culturales, por más que nos lo hayan repetido en el pasado.

Tampoco es posible discernir si estos diseños representan vivencias reales o míticas, a través de conceptos pictóricos que son hoy para nosotros incomprensibles; o si son signos ideográficos que expresan una idea por medio de un orden de ubicación, a manera de articulación entre los diferentes tonos utilizados y sus diferentes variantes.

Ahora bien, la labor aquí realizada sí nos debe poner en mejores condiciones cognoscitivas para abordar los múltiples temas de investigación relacionados con el uso de la paleta de colores en el arte rupestre y sus funciones, el establecimiento de grupos de similitud, etc. Ella puede orientar los esfuerzos académicos e insertar los nuevos descubrimientos que, incorporados otros medios y métodos de investigación, deben permitirnos avanzar en la búsqueda de las respuestas que hoy no poseemos.

\section{Bibliografía}

Alonso, José R.

1991a "Arte rupestre en Punta del Este, Cuba. Los conjuntos combinados no concéntricos". En Estudios Culturales, <www. estudiosculturales2003.es>.

1991b "Arte rupestre en Punta del Este, Cuba. Los conjuntos de líneas concéntricas circulares con círculo interior excéntrico". En Estudios Culturales, <www.estudiosculturales2003.es $>$.

1991c "Arte rupestre en Punta del Este, Cuba. Los conjuntos de líneas concéntricas circulares negras". En Estudios Culturales, $<$ www.estudiosculturales2003.es $>$.

1991d "Arte rupestre en Punta del Este, Cuba. Los conjuntos de líneas concéntricas circulares rojas". En Estudios Culturales, $<$ www.estudiosculturales2003.es >

1992 Arte Rupestre en Punta del Este: estética y símbolo, estructura y análisis. Tesis de grado. Dr. Esteban Maciques, tutor. Departamento de Historia del Arte, Facultad de Artes y Letras, Universidad de La Habana.

1993 "Ortiz y la Cueva del Templo o el informe de Don Fernando". Conferencia Científica Internacional La Ilustración: Luces y sombras en la historia de América. 1793-1993. Bicentenario de la Sociedad Económica de Amigos del País. Instituto de Literatura y Lingüística. Ciudad de La Habana. En Revista del Centro de Estudios Avanzados de Puerto Rico y el Caribe. 18. San Juan.

1994 "Artes aborígenes en Cuba. Para un acercamiento teórico-metodológico a esta producción antigua”. En Primer Encuentro Internacional de Historia del Arte La Historia del Arte hoy: análisis y pronóstico. Departamento de Historia del Arte, Facultad de Artes y Letras, Universidad de La Habana.

2001 "Ortiz y la Cueva del Templo o el inédito informe de Don Fernando". En Boletín del Gabinete de Arqueología (1): 45-55, Oficina del Historiador de la Ciudad, La Habana.

2003 "Un modelo de análisis a una variante gráfica en arte rupestre: las series de círculos concéntricos rojos y negros al- 
ternos”. En Rupestreweb, <http://rupestreweb.tripod.com/series.html $>$.

2004 "Panorama histórico-crítico sobre el estudio del arte rupestre de Punta del Este, Cuba". En Rupestreweb, <http://rupestreweb.tripod.com/puntadeleste.html $>$.

Fernández, Racso.

1994 "El arte rupestre en las cuevas funerarias aborígenes de Cuba". En Casimba, Año 5, Serie 1 (6): 5-11, La Habana.

González, José; Fernández, Racso; Gutiérrez, Divaldo; Carmenate, Hilario; Chinique, Yadira; Rodríguez, Dyalvis

2007 "Reporte del trabajo realizado en 13 de las estaciones de arte rupestre de la provincia de Pinar del Río, como parte del Proyecto de evaluación y diagnóstico del patrimonio sociocultural de Cuba" (inédito). Archivos del Instituto Cubano de Antropología, La Habana.

Gutiérrez, Divaldo, Fernández, Racso; González, José; et al.

2009 "Arte Rupestre Cubano". Serie Mapas plegables etnológicos de Cuba, Ed. Geo, GCIAR, Fundación Fernando Ortiz e Instituto de Antropología, La Habana.

Gutiérrez, Divaldo, Fernández, Racso; González, José; Carmenate, Hilario; Chinique, Yadira; Rodríguez, Dyalvis

2009 "El Arte Rupestre del Parque Nacional Viñales, Pinar del Río, Cuba. Registro y Documentación”. En Cuba Arqueológica II (2), <http://www.cubaarqueologica. org/>.

Herrera Fritot, René.

1938a "Informe sobre una exploración arqueológica a Punta del Este, Isla de Pinos, realizada por el Museo Antropológico Montané de la Universidad de La Habana. Localización y estudio de una cueva con pictografías y restos de un ajuar aborigen". En Universidad de La Habana, 3 (20-21): 25-59. La Habana.

1938b "Las pinturas rupestres y el ajuar ciboney en Punta del Este, Isla de Pinos". En Revista de Arqueología, 1 (2): 50-61. La Habana.

1938c "Comunicación sobre la Cueva de Punta del Este, Isla de Pinos, sus pictografías y los hallazgos de un ajuar siboney". En Boletín Bibliográfico de Antropología Americana, 2 (4): 105-108, México, D. F.

1939 "Discusión sobre el posible origen de las pictografías de Punta del Este, Isla de Pinos". Sociedad Cubana de Historia Natural Felipe Poey, Memorias, XIII, (5): 307-314, La Habana.

Maciques, Esteban

1983 "El estilo de círculos concéntricos: contraposición de dos estilos pictográficos en Punta del Este". (Inédito), Museo Antropológico Montané, Universidad de La Habana, Cuba.

Morales P., Osvaldo

1947 "Arqueología cubana. Resumen de las actividades durante el año de 1946: visitas a Punta del Este (Isla de Pinos) y cayos al este de Caibarién”. En Revista de Arqueología y Etnología, año I, época III, (4-5, ene-dic): 13, La Habana.

Núñez J., Antonio

1947 "Nuevos descubrimientos arqueológicos en Punta del Este, Isla de Pinos". En Universidad de La Habana, año XII, (73. 74-75, jul-dic): 213-247, La Habana.

1985 Arte Rupestre de Cuba. Ed. Jaca Book, Torino.

1995 "Nuevas investigaciones en el arte rupestre de Cuba". En Congreso Internacional LV Aniversario de la Sociedad Espeleológica de Cuba, La Habana.

1967 Cuevas y Pictografías. Ed. Revolucionaria, La Habana.

1975 Cuba: Dibujos Rupestres. Ed. (Conj) Ciencias Sociales e Industrial Grafica S.A., Lima.

Ortiz, Fernando

s/f "Isla de Pinos. Los descubrimientos arqueológicos" (informe manuscrito). Fondo Fernando Ortiz, Carpeta 10, Arqueología (II), Legajos 42-46, Archivo de Literatura del Instituto de Literatura y Lingüística (ILL), La Habana.

2008 La Cueva del Templo. Isla de Pinos. Los descubrimientos arqueológicos. Fundación Fernando Ortiz, compilación y prólogo de Pedro Pablo Godo y Ulises González, La Habana. 
Pereira, Oscar

2004 "La Confluencia del arte rupestre aborigen y africano en las cuevas de Cuba. Estudio Preliminar". (Resumen de ponencia). En CD-R II Taller internacional de Arte Rupestre, 19-23 de abril, La Habana.

Ramírez C., Fernando

1959 Excerta de una Isla Mágica. Editorial Olimpo, México D. F.

Romero, Alejandro

2004 "El arte rupestre en la provincia de Sancti Spíritus, Cuba". En CD Memoria del II Taller Internacional de Arte Rupestre, La Habana.

Royo G., Fernando

1939 "El misterio secular de la Cueva de Punta del Este". Sociedad Cubana de Historia
Natural Felipe Poey, Memorias, XIII (5): 289-305, La Habana.

Matos, Martin

1985 "Las culturas de los círculos concéntricos: computación aborigen”. En Santiago, Revista de la Universidad de Oriente (59), Santiago de Cuba.

1987 "Un enigma con posibilidades de solución: la cultura de los círculos concéntricos". En Santiago, Revista de la Universidad de Oriente (67), Santiago de Cuba.

Universidad de Puerto Rico

2006 "Uno de los primeros grupos agricultores-alfareros en llegar a Borikén fue el de los saladoides (también conocidos como Igneri)". En < http://www.universia.pr/ culturaindigena $>$. 